\title{
The Prevalence and Risks of Inappropriate Combination of Aspirin and Warfarin in Clinical Practice: Results From WARFARIN-TR Study
}

\author{
Salih Kılıç1, Ahmet Çelik², Elif Çekirdekçi³, Servet Altay4, Deniz Elçik ${ }^{5}$, Mehmet Kadri Akboğa6, \\ Mine Durukan7, Çağrı Yayla6, Mehdi Zoghi1
}

\author{
${ }^{1}$ Department of Cardiology, Ege University School of Medicine, İzmir, Turkey \\ ${ }^{2}$ Department of Cardiology, Mersin University School of Medicine, Mersin, Turkey \\ ${ }^{3}$ Clinic of Cardiology, Tekirdağ Çorlu District State Hospital, Tekirdağ, Turkey \\ ${ }^{4}$ Clinic of Cardiology, Edirne Sultan Murat 1. State Hospital, Edirne, Turkey \\ ${ }^{5}$ Clinic of Cardiology, Ankara Research and Training Hospital, Ankara, Turkey \\ ${ }^{6}$ Clinic of Cardiology, Türkiye Yüksek İhtisas Hospital, Ankara, Turkey \\ ${ }^{7}$ Clinic of Cardiology, Mersin City Research and Training Hospital, Mersin, Turkey
}

Background: The use of warfarin and aspirin in combination is restricted to limited patients under relevant guidelines.

Aims: To evaluate the prevalence of the inappropriate combination of aspirin and warfarin therapy in daily practice and its risks.

Study Design: Cross-sectional study.

Methods: The awareness, efficacy, safety, and time in the therapeutic range of warfarin in the Turkish population study is a multi-center observational study that includes 4987 patients using warfarin for any reason between January 1, 2014, and December 31, 2014. To determine the prevalence of inappropriate combination use in daily practice, all patients who had a history of atherosclerotic disease (ischemic heart disease, peripheral artery disease) or cerebrovascular disease $(n=1498)$ were excluded. The data of 3489 patients were analyzed. We defined inappropriate combination as all patients who received aspirin and warfarin regardless of the indication for warfarin use, under the direction of the European Society of Cardiology guideline recommendation.

Results: The mean age of patients was $59.2 \pm 13.8$ years $(41.8 \%$ male). The prevalence of the inappropriate use of warfarin and aspirin combination was $20.0 \%$. The prevalence of combination therapy in patients with a primary indication for mechanical heart valve, nonvalvular atrial fibrillation, and other reasons was $20.5 \%, 18.7 \%$, and
$21.0 \%$, respectively. Multivariate logistic regression analysis revealed that age (odds ratio, 1.009; 95\% confidence interval, 1.002-1.015; $\mathrm{p}=0.010$ ), heart failure (odds ratio, $1.765 ; 95 \%$ confidence interval, 1.448-2.151; $\mathrm{p}<0.001$ ), smoking (odds ratio, $1.762 ; 95 \%$ confidence interval, 1.441-1.153; $<<0.010$ ), chronic kidney disease (odds ratio, 2.057; $95 \%$ confidence interval, 1.494-2.833; $<<0.001$ ), and deep vein thrombosis (odds ratio, $0.463 ; 95 \%$ confidence interval, 0.229 $0.718 ; \mathrm{p}=0.001$ ) were independent predictors of combination therapy $\left(r^{2}=0.66\right)$. The mean time in therapeutic range of patients receiving combination therapy was significantly lower than in those on warfarin monotherapy $(51.6 \pm 27.05$ vs. $54.7 \pm 23.93 ; \mathrm{p}=0.006)$. Overall, $19.4 \%$ $(\mathrm{n}=677)$ of patients had a bleeding event (major bleeding $13.0 \%$, $\mathrm{n}=88$ ) within a year. Percentages of patients with combination therapy were significantly higher in patients with major bleeding than in patients without major bleeding ( $29.5 \%$ vs. $19.7 \%$; $p=0.023)$.

Conclusion: Our study demonstrated that $20.0 \%$ of patients taking warfarin use concomitant aspirin inappropriately in daily practice. Patients receiving aspirin with warfarin were demonstrated to have more comorbidities, lower time in therapeutic range levels, and higher bleeding rates.

Keywords: Anticoagulants, antiplatelet drugs, aspirin, inappropriate prescribings, Warfarin

Address for Correspondence: Salih Kılıç, Department of Cardiology, Ege University School of Medicine, İzmir, Turkey

Phone: +90555558 $8341 \quad$ e-mail: kilicsalihhh@gmail.com ORCID ID: orcid.org/0000-0002-3579-3747

Received: 31 October $2017 \quad$ Accepted: 3 August 2018 • DOI: 10.4274/balkanmedj.2017.1472

Available at www.balkanmedicaljournal.org

Cite this article as:

Kılıç S, Celik A, Cekirdekçi E, Altay S, Elçik D, Akboğa MK, et al. The Prevalence and Risks of Inappropriate Combination of Aspirin and Warfarin in Clinical Practice:

Results From WARFARIN-TR Study. Balkan Med J 2019;36:17-22

${ }^{\circ}$ Copyright 2019 by Trakya University Faculty of Medicine / The Balkan Medical Journal published by Galenos Publishing House. 
Warfarin is used commonly in atrial fibrillation (AF), mechanical heart valve (MHV) replacement, and other diseases such as chronic pulmonary embolism, ischemic stroke, and deep vein thrombosis (DVT). Aspirin in addition to warfarin can be used to improve antithrombotic activity. Although the combination of aspirin and warfarin results in a significant increase (up to 1.5to 2-fold) in the risk of bleeding, it does not add any benefit in stroke and cardiovascular events $(1,2)$. Both the AF guidelines of the European Society of Cardiology (ESC) and American College of Cardiology/American Heart Association (ACC/AHA) do not recommend adding aspirin to warfarin treatment except in patients who are receiving warfarin for AF and have had an acute ischemic event or undergone coronary revascularization during the last year $(3,4)$. However, for patients with MHV, there are different recommendations between the ACC/AHA and ESC guidelines regarding the use of aspirin in addition to warfarin. The ACC/AHA valvular heart disease guideline recommended that aspirin should be routinely added to warfarin therapy (class 1, level a). However, the ESC valvular heart disease guideline does not recommend adding aspirin to warfarin therapy routinely. It recommends that low-dose aspirin (75-100 mg/day) may be considered in the case of concomitant atherosclerotic disease (class $2 \mathrm{~b}$, level c) or should be considered after thromboembolism despite an adequate international normalized ratio (INR) (class 2a, level c) $(5,6)$. The existence of such significant differences between the two guidelines can lead to physicians having different treatment recommendations for patients with MHV. Besides this difference, the inappropriate use of aspirin with warfarin is frequently among patients who take them concomitantly for any reason as directed by both community-based prescribers and randomized studies (7-12). Against this background, the objectives of the present study are to evaluate the prevalence of the inappropriate combination of aspirin and warfarin and to describe which patients are currently receiving combination therapy in daily practice. For this purpose, the data of the The awareness, efficacy, safety, and time in the therapeutic range of warfarin in the Turkish population (WARFARIN-TR) study were evaluated.

\section{MATERIALS AND METHODS}

The main results of the WARFARIN-TR study have been published previously $(13,14)$. In summary, The WARFARIN-TR study included 42 centers from 24 cities in Turkey from January 1, 2014, to December 31,2014 . The study protocol was approved by the local ethics committee. During routine clinical follow-up, the patients' data were recorded. The INR values of patients were recorded from digital hospital records. All consecutive patients $(n=4987)$ using warfarin regularly for any reason and attending routine INR monitoring were entered into the study. Patients who were not followed-up regularly, and under 18 years old were excluded from the study. For patients with warfarin due to non-valvular AF (NVAF) and other reasons, the target INR was 2.5 (range, 2.0-3.0). Also, the target INR value was 3.0 (2.5-3.5) for patients with MHV. The time in therapeutic range (TTR) was calculated according to F.R. Roosendaal's algorithm with linear interpolation (15). The $\mathrm{CHA}_{2} \mathrm{DS}_{2}$-VASc [heart failure (HF), hypertension, age $\geq 75$, diabetes, stroke, vascular disease, age 65-74 years, female sex] score of patients with NVAF was calculated at the time as the interview (3). Each risk factor except age $\geq 75$ ( 2 points) and stroke ( 2 points) at this score is one point. Transfusion of at least 2 units of blood, reduction in the hemoglobin level of at least 2 $\mathrm{g} / \mathrm{L}$, or symptomatic bleeding in a critical area were determined as major bleeding. Other bleeding was considered minor bleeding. All consecutive patients who were using warfarin for any reason during the last year were included in the WARFARIN-TR study without considering whether there were any acute ischemic events or revascularization during the last year. Hence, it is not clear in the WARFARIN-TR study how many patients had acute ischemic events or revascularization during the last year. Therefore, for the present study, all patients who had a history of atherosclerotic disease (ischemic heart disease, peripheral artery disease) or cerebrovascular disease were excluded from the study $(n=1498$; $30.03 \%$ of all patients). The data of the remaining 3489 patients that did not have an indication for aspirin use under the direction of the ESC guidelines were analyzed. Although it is not proven by a study, the recommendations of the ESC guidelines are more applied in daily practice in Turkey than are the ACC/AHA guidelines. Because of this, in the present study, we have defined combination treatment as inappropriate for all patients who received aspirin and warfarin regardless of the warfarin use indication, under the direction of the ESC guidelines recommendation.

\section{Statistical analysis}

Continuous variables were presented as the mean \pm standard deviation, and categorical variables were expressed as number and percentage $(\%)$. Continuous variables were compared with the Student's t-test or the Mann-Whitney U Test. A chi-square test or Fisher's exact test was used to compare categorical variables. The homogeneity of variance was tested with Levene's test. Independent predictors of combination therapy were determined by logistic regression analysis. Possible factors that were identified with univariate analyses were entered into the logistic regression analysis. The Statistical Package for the Social Sciences (SPSS for Windows, Version 20.0, SPSS Inc., Chicago, IL, USA) was used for the statistical analysis. A p value less than .05 was accepted as statistically significant.

\section{RESULTS}

A total of 3489 patients (males $41.8 \%$, mean age $59.2 \pm 13.8$ years) were included. The prevalence of combination therapy was $20.0 \%$. The primary indication for warfarin use for MHV, NVAF, and other reasons were $47 \%, 35.5 \%$, and $17.5 \%$, respectively. The prevalence of combination therapy in patients using warfarin due to MHV, NVAF, and other reasons was $20.5 \%, 18.7 \%$, and $21.0 \%$, respectively. The demographic characteristics of the warfarin monotherapy group and combination therapy group are summarized in Table 1. The combination therapy group was found to be older and had a higher prevalence of male gender and history of smoking, HF, and chronic kidney disease (CKD). There was no difference between the groups regarding the indication for warfarin use. The mean TTR (51.6 \pm 27.05 vs. $54.7 \pm 23.93 ; \mathrm{p}=0.006)$ and number of INR examined during one year $(9.65 \pm 3.08$ vs. 
$10.5 \pm 3.39 ; \mathrm{p}<0.001)$ were significantly lower in the combination therapy group when compared with the warfarin monotherapy group (Table 2). The mean $\mathrm{CHA}_{2} \mathrm{DS}_{2}$-VASc score was $2.8 \pm 1.29$ in patients with NVAF, and there were no significant differences between groups. Although the $\mathrm{CHA}_{2} \mathrm{DS}_{2}$-VASc score was 0,36 patients with NVAF had been prescribed warfarin, and 6 of these patients received combination therapy. Moreover, 26.5\% (36/136) of patients with a risk score of 1 , and $17.8 \%$ (117/996) with a risk score of $\geq 2$ were receiving combination therapy. Multivariate logistic regression analysis revealed that age [odds ratio (OR),
1.009; 95\% confidence interval (CI), 1.002-1.015; $\mathrm{p}=0.010]$, HF (OR, 1.765; 95\% CI, 1.448-2.151; $\mathrm{p}<0.001$ ), smoking (OR, 1.762; 95\% CI, 1.441-1.153; p<0.010), CKD (OR, 2.057; 95\% CI, $1.494-$ 2.833; $\mathrm{p}<0.001$ ), and DVT (OR, 0.463; 95\% CI, 0.229-0.718; $\mathrm{p}=0.001)$ were independent predictors of combination therapy $\left(\mathrm{r}^{2}=0.66\right)$ (Table 3). Overall, $667(19.4 \%)$ patients had a bleeding event $(13.0 \%, \mathrm{n}=88$, major bleeding). Demographic characteristics of patients with and without major bleeding are summarized in Table 4. There were no significant differences between patients with and without major bleeding except combination therapy and a

TABLE 1. Comparison of baseline characteristics of patients with combination therapy and warfarin monotherapy

\begin{tabular}{|c|c|c|c|c|c|}
\hline \multicolumn{2}{|l|}{ Description } & All patients & $\begin{array}{l}\text { Combination therapy } \\
\qquad(\mathrm{n}=697)\end{array}$ & $\begin{array}{l}\text { Warfarin monotherapy } \\
\qquad(\mathrm{n}=2792)\end{array}$ & $\mathrm{p}$ \\
\hline \multicolumn{2}{|l|}{ Age, years, mean \pm SD } & $59.2 \pm 13.8$ & $61.1 \pm 13$ & $58.8 \pm 14$ & $<0.001$ \\
\hline \multicolumn{2}{|l|}{ Male, \% (n) } & $41.8(1458)$ & $46.6(325)$ & $40.6(1133)$ & 0.004 \\
\hline \multicolumn{2}{|l|}{ Hypertension, \% (n) } & $50.9(1776)$ & $52.1(363)$ & $50.6(1413)$ & 0.487 \\
\hline \multicolumn{2}{|l|}{ Diabetes mellitus, \% (n) } & $639(18.3)$ & $20.4(142)$ & 17.8 (497) & 0.116 \\
\hline \multicolumn{2}{|l|}{ Smoking, \% (n) } & $18.7(651)$ & $25.8(180)$ & $16.9(471)$ & $<0.001$ \\
\hline \multicolumn{2}{|l|}{ Hyperlipidemia, \% (n) } & $17.1(595)$ & $18.2(127)$ & $1689(468)$ & 0.360 \\
\hline \multicolumn{2}{|l|}{ Heart failure, \% (n) } & $19.3(675)$ & $28.7(200)$ & $17,0(475)$ & $<0.001$ \\
\hline \multicolumn{2}{|c|}{ Chronic kidney disease, $\%(n)$} & $5.4(190)$ & $9.6(67)$ & $4.4(123)$ & $<0.001$ \\
\hline \multicolumn{2}{|c|}{ Pulmonary embolism, \% (n) } & $5.7(199)$ & $5.7(40)$ & $5.7(159)$ & 0.964 \\
\hline \multicolumn{2}{|c|}{ Deep vein thrombosis, $\%(n)$} & $6.5(226)$ & $3.4(24)$ & $7.2(202)$ & $<0.001$ \\
\hline \multirow{3}{*}{ Reason for Warfarin use } & NVAF, \% (n) & $35.5(1237)$ & $33.3(232)$ & $36.0(1005)$ & \multirow{3}{*}{0.394} \\
\hline & MHV, \% (n) & $47.1(1643)$ & $48.4(337)$ & $46.8(1306)$ & \\
\hline & Other, \% (n) & $17.5(609)$ & $18.4(128)$ & $17.2(481)$ & \\
\hline
\end{tabular}

TABLE 2. Comparison of laboratory results, risk scores and bleeding complications of the patients with combination therapy and warfarin monotherapy

\begin{tabular}{|c|c|c|c|c|}
\hline Description & $\begin{array}{l}\text { All patients } \\
(\mathrm{n}=3489)\end{array}$ & $\begin{array}{l}\text { Combination therapy } \\
\qquad(n=697)\end{array}$ & $\begin{array}{l}\text { Warfarin monotherapy } \\
\qquad(\mathrm{n}=2792)\end{array}$ & $\mathrm{p}$ \\
\hline $\mathrm{TTR} \% \pm \mathrm{SD}$ & $54.1 \pm 24.61$ & $51.6 \pm 27.05$ & $54.7 \pm 23.93$ & 0.006 \\
\hline INR examined during one year & $10.3 \pm 3.3$ & $9.65 \pm 3.08$ & $10.5 \pm 3.39$ & $<0.001$ \\
\hline $\mathrm{CHA}_{2} \mathrm{DS}_{2}$-VASc $(\mathrm{n}=1237)^{\uparrow}$ & $2.8 \pm 1.29$ & $2.7 \pm 1.32$ & $2.8 \pm 1.28$ & 0.429 \\
\hline HAS-BLED score & $1.4 \pm 1.15$ & $1.9 \pm 1.20$ & $1.3 \pm 1.11$ & $<0.001$ \\
\hline HAS-BLED score $\geq 3 \%$, (n) & $17.9(587)$ & $29.4(196)$ & $15.0(391)$ & $<0.001$ \\
\hline All bleeding \%, (n) & $19.4(677)$ & $30.8(215)$ & $16.5(462)$ & $<0.001$ \\
\hline Major bleeding \%, (n) & $2.5(88)$ & $3.7(26)$ & $2.2(62)$ & 0.023 \\
\hline Minor bleeding $\%,(n)$ & $16.9(589)$ & $27.1(189)$ & $14.3(400)$ & $<0.001$ \\
\hline
\end{tabular}

IPatients use warfarin for non-valvular atrial fibrillation

INR: international normalized ratio; SD: standard deviation TTR: time in therapeutic range

TABLE 3. Predictors of combination therapy in multivariate logistic regression analysis

\begin{tabular}{|c|c|c|c|}
\hline Variable & OR & $95 \% \mathrm{CI}$ & $\mathrm{p}$ \\
\hline Age & 1.009 & $1.002-1.015$ & 0.010 \\
\hline Smoking & 1.762 & $1.441-1.153$ & $<0.010$ \\
\hline Heart failure & 1.765 & $1.448-2.151$ & $<0.001$ \\
\hline Deep vein thrombosis & 0.463 & $0.229-0.718$ & 0.001 \\
\hline Chronic kidney disease & 2.057 & $1.494-2.833$ & $<0.001$ \\
\hline
\end{tabular}


TABLE 4. Comparison characteristics and laboratory parameters of patients with and without major bleeding

\begin{tabular}{|c|c|c|c|c|}
\hline Description & $\begin{array}{l}\text { All patients } \\
(\mathrm{n}=3489)\end{array}$ & $\begin{array}{l}\text { Major bleeding } \\
\quad(\mathrm{n}=88)\end{array}$ & $\begin{array}{l}\text { Non-bleeding } \\
(\mathrm{n}=3401)\end{array}$ & $\mathrm{p}$ \\
\hline Age, years, mean \pm SD & $59.2 \pm 13.8$ & $59.2 \pm 15$ & $59.2 \pm 13.74$ & 0.292 \\
\hline Male, $\%(n)$ & $41.8(1458)$ & $47.7(42)$ & $41.6(1416)$ & 0.253 \\
\hline Hypertension, \% (n) & $50.9(1776)$ & $50.0(44)$ & $50.9(1732)$ & 0.864 \\
\hline Diabetes mellitus, \% (n) & $18.3(639)$ & $15.9(14)$ & $18.4(625)$ & 0.555 \\
\hline Smoking, \% (n) & $18.7(651)$ & $21.6(19)$ & $18.6(632)$ & 0.475 \\
\hline Heart failure, \% (n) & $19.3(675)$ & $26.1(23)$ & $19.2(652)$ & 0.102 \\
\hline Chronic kidney disease $\%(n)$ & $5.4(190)$ & $10.2(9)$ & $5.3(181)$ & 0.045 \\
\hline Pulmonary embolism, \% (n) & $57(199)$ & $3.4(3)$ & $5.8(196)$ & 0.347 \\
\hline Deep vein thrombosis, \% (n) & $6.5(226)$ & $5.7(5)$ & $6.5(221)$ & 0.759 \\
\hline $\mathrm{TTR}, \% \pm \mathrm{SD}$ & $54.1 \pm 24.61$ & $51.0 \pm 23.60$ & $54.2 \pm 24.64$ & 0.027 \\
\hline
\end{tabular}

history of CKD. Percentages of patients with combination therapy were significantly higher in patients with major bleeding than in patients without major bleeding $(29.5 \%$ vs. $19.7 \%$; $p=0.023)$. Also, the mean TTR values of patients with major bleeding were significantly lower than the mean TTR values of patients without major bleeding ( $51.0 \pm 23.60$ vs. $54.2 \pm 24.64$; $\mathrm{p}=0.027)$.

\section{DISCUSSION}

The present study has determined that one-fifth of patients who receive warfarin for any indication are receiving aspirin inappropriately in daily practice. In addition, patients with combination therapy were more likely to be older with a history of $\mathrm{HF}, \mathrm{CKD}$, and smoking. Furthermore, patients with combination therapy were more likely to have major bleeding compared with warfarin monotherapy. Both ESC and ACC/AHA AF guidelines do not recommend aspirin in addition to warfarin except in patients who have had an acute ischemic event or undergone coronary revascularization during the last year $(3,4)$. Similar to AF patients, there is no recommendation to administer or prescribe aspirin in addition to warfarin to patients who are on warfarin for other reasons. However, although there is no recommendation, our results had shown that one-fifth of patients who use warfarin for AF or other reasons were receiving combination therapy inappropriately. Previous studies have shown that the combination of aspirin and warfarin did not lead to reduced stroke or vascular events, and resulted in an increased risk of bleeding in AF patients $(16,17)$. However, randomized trials that evaluated new oral anticoagulants have demonstrated that $20 \%-36 \%$ of patients receiving warfarin for NVAF also received aspirin concomitantly (18-20). In these studies, a remarkable percentage of patients receive aspirin without having a history of atherosclerotic disease. Previous studies had shown that widespread use of combination therapy appears to be because of the presence of multiple comorbidities $(7,18-20)$.
Similar to these previous studies, our results showed that the presence of comorbidities such as HF, CKD, smoking, and older ages were strong independent predictors of combination therapy. Smoking, CKD, and older age are known to be risk factors for the development of cardiovascular disease. Similarly, HF has a high potential for the development of cardiovascular events. For this reason, when physicians prescribe combination therapy for a potentially complementary antiplatelet and anticoagulant action, they should consider the comorbidities or risk factors that may cause cardiovascular events. However, we were unable to determine whether patients received combination therapy as directed by a physician or their own initiative. As it is widely believed that aspirin is beneficial for reducing the risk of heart attack, and it is easy to get aspirin in Turkey without a prescription, many patients may have been self-administering aspirin as part of their therapy without the knowledge of their physician. On the other hand, when the $\mathrm{CHA}_{2} \mathrm{DS}_{2}$-VASc score was taken into account, our results showed that many patients with warfarin for NVAF receive warfarin or combination therapy even though they do not have an indication. This result shows that some physicians do not consider the $\mathrm{CHA}_{2} \mathrm{DS}_{2}$-VASc score that is recommended by the guidelines for NVAF patients when starting warfarin therapy. ESC Valvular Diseases guideline recommends adding low-dose aspirin to warfarin treatment in patients with simultaneous MHV and atherosclerotic heart disease (Class 2a) (21). The routine addition of aspirin to warfarin in patients with MHV, however, is not recommended. Despite the restricted indication of the ESC guideline, ACC/AHA valvular disease guideline recommends lowdose aspirin in all patients with MHV (Class 1) $(21,22)$. In their study with 4557 patients, Johnson et al. (23) found that $47.8 \%$ of patients who were taking warfarin for AF, 27.4\% for venous thromboembolism, $11 \%$ for $\mathrm{MHV}$, and $6.6 \%$ for stroke or transient ischemic attack, $38.5 \%$ were receiving inappropriate combination 
therapy according to the American College of Chest Physician guideline.

In their study with $360 \mathrm{AF}$ and MHV patients, Turan et al. (24) noted that $25.8 \%$ of the patients were receiving combination therapy. The same study also observed that $21.1 \%$ of AF patients and $32.7 \%$ of MHV patients were receiving combination therapy. In our study, similar to other indications, $20.5 \%$ of patients taking warfarin for $\mathrm{MHV}$ were using aspirin concomitantly. Different recommendations listed by the ESC and ACC/AHA guidelines for MHV patients regarding whether to use aspirin regularly or not might result in discrepancies among physicians who are following these guidelines. When evaluated from the perspective of the ESC guideline, there appears to be a high rate of inappropriate aspirin use among patients. When evaluated from the perspective of the ACC/AHA guideline, it appears that very few patients are receiving aspirin. However, as we mentioned above, the recommendations of the ESC guidelines are applied more in daily practice in Turkey when compared with those of the ACC/AHA guidelines. For this reason, our results have indicated that one-fifth of patients on warfarin for MHV receive aspirin inappropriately. As mentioned above, concomitant comorbidities are predictors of combination therapy use. Also, lower TTR levels might be a reason for combination therapy. Physicians might have preferred aspirin in patients with lower TTR to an agent with better antiplatelet and anticoagulant action. Similarly, the lower number of INR examined in one year demonstrated that these patients do not have regular follow-ups indirectly and physicians might have preferred combination therapy for these individuals. Bleeding is one of the most important events in patients treated with warfarin. Studies have shown that adding aspirin to warfarin did not reduce stroke, systemic embolism, and myocardial infarction, but rather, led to an increased risk of bleeding (25-27). Similar to previous studies, we demonstrated that the number of both major and minor bleeding events is significantly higher in patients with combination therapy. Also, combination therapy was a predictor of major bleeding. New-generation oral anticoagulants, which can be alternatives to the long-used warfarin, are currently being used. These drugs have significant advantages of not requiring close follow-up, not having food-drug interactions, and causing less bleeding with similar efficacy $(9,10,18,28)$. New-generation oral anticoagulants with proven efficacy may be preferred instead of adding aspirin to warfarin to decrease the risk of thromboembolism in patients who fail to achieve effective TTR values or cannot attend regular follow-ups.

The most important limitation of this study is the lack of evaluation of events, such as stroke and myocardial infarction, in patients who experienced them during the course of the study.

Our study, which reflects daily practice, demonstrated that a high proportion of patients taking warfarin concomitantly use aspirin inappropriately. Patients receiving aspirin with warfarin were shown to have more comorbidities, lower TTR levels, and higher bleeding rates.

Acknowledgements: We thank the following individuals for their contributions to our WARFARIN-TR Study group. Servet İzci, Mehmet Ali Kobat, Ahmet Hakan Ateş, Abdülkadir Çakmak, Yasin Çakıllı, Hüseyin Altuğ Çakmak,
Abdülmecit Afşin, Ahmet İlker Tekkeşin, Gönül Açıssarı, Mehmet Erdem Memetoğlu, Fatma Özpamuk Karadeniz, Ekrem Şahan, Mehmet Hayri Alıcı, Yüksel Dereli, Ümit Yaşar Sinan, Nazlı Akciğer, Yusuf Aslantaş, Tolga Han Efe, Ali Sabri Seyis, Zeynep Yapan Emren, Kamil Tuluce, Nurullah Çetin, Ali Kemal Kalkan, Fatih Aytemiz, Selcen Yakar Tuluce, Mehmet Kıs, Ahmet Gündeş, Özge Kurmuş, Şeyda Günay, Hamza Duygu, Özcan Başaran, Sinan İnci, Mehmet Ballı, Özgen Şafak, Fatma Köksal, Barış Çelebi, Buğra Özkan, Murat Biteker, Hasan Yücel, Yakup Altaş, Selim Topçu, Lütfü Aşkın, Kerem Özbek, Volkan Emren, Kaya Özen, Eyüp Özkan.

Conflict of Interest: No conflict of interest was declared by the authors.

Financial Disclosure: No financial disclosure was declared by the authors.

\section{REFERENCES}

1. Johnson SG, Rogers K, Delate T, Witt DM. Outcomes associated with combined antiplatelet and anticoagulant therapy. Chest 2008;133:948-54.

2. Shireman TI, Howard PA, Kresowik TF, Ellerbeck EF. Combined anticoagulantantiplatelet use and major bleeding events in elderly atrial fibrillation patients. Stroke 2004;35:2362-7.

3. Kirchhof P, Benussi S, Kotecha D, Ahlsson A, Atar D, Casadei B, et al. 2016 ESC Guidelines for the management of atrial fibrillation developed in collaboration with EACTS. Eur Heart J 2016;37:2893-962.

4. January CT, Wann LS, Alpert JS, Calkins H, Cigarroa JE, Cleveland JC, et al. 2014 AHA/ACC/HRS guideline for the management of patients with atrial fibrillation: a report of the American College of Cardiology/American Heart Association Task Force on practice guidelines and the Heart Rhythm Society. Circulation 2014;130:199-267.

5. Baumgartner H, Falk V, Bax JJ, De Bonis M, Hamm C, Holm PJ, et al. 2017 ESC/ EACTS Guidelines for the management of valvular heart disease. Eur Heart $\mathrm{J}$ 2017;38:2739-91.

6. Nishimura RA, Otto CM, Bonow RO, Carabello BA, Erwin JP, Fleisher LA, et al. 2017 AHA/ACC Focused Update of the 2014 AHA/ACC Guideline for the Management of Patients With Valvular Heart Disease: A Report of the American College of Cardiology/American Heart Association Task Force on Clinical Practice Guidelines. Circulation 2017;135:1159-95.

7. Johnson SG, Witt DM, Eddy TR, Delate T. Warfarin and antiplatelet combination use among commercially insured patients enrolled in an anticoagulation management service. Chest 2007;131:1500-7.

8. Turan B, Demir H, Mutlu A, Daşlı T, Erkol A, Erden İ. Inappropriate combination of warfarin and aspirin. Anatol J Cardiol 2016;16:189-96.

9. Wallentin L, Yusuf S, Ezekowitz MD, Alings M, Flather M, Franzosi MG, et al. Efficacy and safety of dabigatran compared with warfarin at different levels of international normalised ratio control for stroke prevention in atrial fibrillation: an analysis of the RE-LY trial. Lancet 2010;376:975-83.

10. Lopes RD, Alexander JH, Al-Khatib SM, Ansell J, Diaz R, Easton JD, et al. Apixaban for reduction in stroke and other ThromboemboLic events in atrial fibrillation (ARISTOTLE) trial: design and rationale. Am Heart J 2010;159:331-9.

11. Turk UO, Tuncer E, Alioglu E, Yuksel K, Pekel N, Ozpelit E, et al. Evaluation of the impact of warfarin time in therapeutic range on outcomes of patients with atrial fibrillation in Turkey: perspectives from the observational, prospective WATER Registry. Cardiol J 2015;22:567-75.

12. Kılıç S, Soner Kemal H, Yüce Eİ, Şimşek E, Yağmur B, Memişoğlu Akgül N, et al. Comparison of Warfarin use in terms of efficacy and safety in two different polyclinics. Anatol J Cardiol 2017;18:328-33.

13. Çelik A, İzci S, Kobat MA, Ateş AH, Çakmak A, Çakıllı Y, et al. The awareness, efficacy, safety, and time in therapeutic range of warfarin in the Turkish population: WARFARIN-TR. Anatol J Cardiol 2016;16:595-600.

14. Kılıç S, Çelik A, Çakmak HA, Afşin A, Tekkeşin Aİ, Açıksarı G, et al. The Time in Therapeutic Range and Bleeding Complications of Warfarin in Different Geographic Regions of Turkey: A Subgroup Analysis of WARFARIN-TR Study. Balkan Med J 2017;34:349-55

15. Rosendaal FR, Cannegieter SC, van der Meer FJ, Briët E. A method to determine the optimal intensity of oral anticoagulant therapy. Thromb Haemost 1993;69:236-9. 
16. Vandvik PO, Lincoff AM, Gore JM, Gutterman DD, Sonnenberg FA, Alonso-Coello $\mathrm{P}$, et al. Primary and secondary prevention of cardiovascular disease: Antithrombotic Therapy and Prevention of Thrombosis, 9th ed: American College of Chest Physicians Evidence-Based Clinical Practice Guidelines. Chest 2012;141(2 Suppl):637-68.

17. Rubboli A, Faxon DP, Juhani Airaksinen KE, Schlitt A, Marín F, Bhatt DL, et al. The optimal management of patients on oral anticoagulation undergoing coronary artery stenting. The 10th Anniversary Overview. Thromb Haemost 2014;112:1080-7.

18. ROCKET AF Study Investigators. Rivaroxaban-once daily, oral, direct factor $\mathrm{Xa}$ inhibition compared with vitamin $\mathrm{K}$ antagonism for prevention of stroke and Embolism Trial in Atrial Fibrillation: rationale and design of the ROCKET AF study. Am Heart J 2010;159:340-7.

19. Connolly SJ, Ezekowitz MD, Yusuf S, Eikelboom J, Oldgren J, Parekh A, et al. Dabigatran versus warfarin in patients with atrial fibrillation. N Engl J Med 2009;361:1139-51.

20. Alexander JH, Lopes RD, Thomas L, Alings M, Atar D, Aylward P, et al. Apixaban vs. warfarin with concomitant aspirin in patients with atrial fibrillation: insights from the ARISTOTLE trial. Eur Heart J 2013;35:224-32.

21. Joint Task Force on the Management of Valvular Heart Disease of the European Society of Cardiology (ESC); European Association for Cardio-Thoracic Surgery (EACTS), Vahanian A, Alfieri O, Andreotti F, Antunes MJ, et al. Guidelines on the management of valvular heart disease (version 2012). Eur Heart J 2012;33:2451-96.

22. Nishimura RA, Otto CM, Bonow RO, Carabello BA, Erwin JP, Fleisher LA, et al. 2017 AHA/ACC Focused Update of the 2014 AHA/ACC Guideline for the Management of Patients With Valvular Heart Disease: A Report of the American
College of Cardiology/American Heart Association Task Force on Clinical Practice Guidelines. J Am Coll Cardiol 2017;70:252-89.

23. Johnson SG, Witt DM, Eddy TR, Delate T. Warfarin and antiplatelet combination use among commercially insured patients enrolled in an anticoagulation management service. Chest 2007;131:1500-7.

24. Turan B, Demir H, Mutlu A, Daşı1 T, Erkol A, Erden İ. Inappropriate combination of warfarin and aspirin. Anatol J Cardiol 2016;16:189-96.

25. Flaker GC, Gruber M, Connolly SJ, Goldman S, Chaparro S, Vahanian A, et al. Risks and benefits of combining aspirin with anticoagulant therapy in patients with atrial fibrillation: an exploratory analysis of stroke prevention using an oral thrombin inhibitor in atrial fibrillation (SPORTIF) trials. Am Heart J 2006;152:967-73.

26. Dentali F, Douketis JD, Lim W, Crowther M. Combined aspirin-oral anticoagulant therapy compared with oral anticoagulant therapy alone among patients at risk for cardiovascular disease: a meta-analysis of randomized trials. Arch Intern Med 2007;167:117-24

27. Dans AL, Connolly SJ, Wallentin L, Yang S, Nakamya J, Brueckmann M, et al. Concomitant use of antiplatelet therapy with dabigatran or warfarin in the Randomized Evaluation of Long-Term Anticoagulation Therapy (RE-LY) trial. Circulation 2013; 127:634-40.

28. Ruff CT, Giugliano RP, Antman EM, Crugnale SE, Bocanegra T, Mercuri M, et al Evaluation of the novel factor Xa inhibitor edoxaban compared with warfarin in patients with atrial fibrillation: design and rationale for the Effective aNticoaGulation with factor xA next GEneration in Atrial Fibrillation-Thrombolysis In Myocardial Infarction study 48 (ENGAGE AF-TIMI 48). Am Heart J 2010;160:635-41. 